\title{
O valor da brancura: considerações sobre um debate pouco explorado no Brasil
}

Luciana Alves

Mestra em educação pela Faculdade de Educação da Universidade de São Paulo, pesquisadora do CENPEC e Professora da Faculdade Sumaré.
Resumo: Este artigo se insere no campo de debates a respeito das desigualdades raciais e tem por objetivo analisar aspecto pouco tratado em estudos brasileiros: as concepções construídas a respeito da brancura. Para a consecução desse objetivo, foram realizadas entrevistas semiestruturadas com dez professores da educação básica, autoclassificados negros ou brancos, em que se buscou apreender o que significou "ser branco" em suas trajetórias de vida. As análises revelam que a brancura é encarada como um ideal ético, educacional, estético e econômico a ser alcançado pelos sujeitos, idealização construída com base na depreciação de outros grupos raciais, notadamente o negro. Conclui-se que as discussões atuais sobre uma educação antirracista podem contribuir para a desconstrução dessa idealização.

Palavras-chave: Relações Raciais. Brancura. Negritude. Diversidade. Educação. 
INTRODUÇÃO

Ao falar em diversidade sempre se corre o risco de enfocar as diferenças, esquecendo-nos de que a definição do diferente depende em grande parte da construção de uma norma ou padrão que serve de medida para os demais grupos. Esse silêncio em relação à norma cria uma zona neutra sobre a qual pouco se tem a dizer e permite que alguns sejam considerados mais iguais que outros.

Nos estudos das relações raciais essa tendência se repete. São vários os trabalhos que se dedicam a analisar as desigualdades tendo como referência o sujeito negro. Embora tais investigações representem um avanço significativo no debate sobre as desigualdades raciais em nosso país, elas geralmente fazem referência apenas ao problema de um “Outro [...] considerado diferente, específico, em contraposição ao humano, universal, o branco" (BENTO, 2002, p. 41).

Para preencher essa lacuna, um conjunto de estudos vem se destacando desde a década de 1990, especialmente nos países de língua inglesa: os estudos críticos da branquitude. São pesquisas que objetivam elucidar o processo de construção da identidade racial branca e as implicações desse processo para a perpetuação do racismo e das desigualdades sociais.

Embora a definição de branquitude seja alvo de disputas, há pelo menos um ponto consensual relativo à sua origem sociohistórica: assim como as demais identidades raciais, esta é considerada um produto da dominação colonial europeia e, portanto, estaria intimamente relacionada à supremacia branca global, sendo impossível conceituá-la sem atentar para as relações de poder que lhe deram origem, o que sugere uma primeira assimetria que impede que se tracem paralelos entre a branquitude e as demais identidades raciais construídas em resposta ou, se preferível, resistência a esta, como a negritude, por exemplo (FRANKENBERG, 1993; HARRIS, 1993; STEYN, 2004). Tal assimetria também impossibilita caracterizar grupos brancos como "diferentes" ou como minorias, a não ser que se trate de minorias étnicas, ocasião em que os traços culturais são considerados tão ou mais distintivos que a raça. A impossibilidade de caracterizar a população branca dentre aquelas consideradas "diversas" não minimiza a necessidade de se refletir a respeito da brancura, em especial nas sociedades consideradas multirraciais, nas quais o racismo, em seus aspectos simbólicos e estruturais, privilegia aqueles que se reconhecem como brancos. 
Em nosso país, a miscigenação é considerada traço definidor da nacionalidade, pois marca uma narrativa de origem para o Brasil moderno (SCHWARCZ, 1993). Mesmo com o discurso de que formamos uma nação mestiça, em 2010, o Censo apontava que 47,7\% dos brasileiros se consideravam brancos, número que embora não represente a maioria da população demonstra que a despeito dos discursos sobre a mestiçagem é possível que sujeitos construam uma identidade branca em nossa sociedade, o que enseja a questão: o que significa ser branco nesse contexto?

Para responder a essa pergunta, ainda que de maneira incipiente, este artigo se insere no campo dos debates a respeito das desigualdades raciais. Seu objetivo é analisar concepções a respeito da brancura, enfocando especialmente, os valores atribuídos a esta. Ou seja, o foco recai sobre as construções simbólicas que se relacionam ao grupo branco no imaginário dos sujeitos da pesquisa.

A escolha por trabalhar com a dimensão simbólica da brancura deixa parcialmente implícita uma discussão importante a respeito das características físicas que permitem a classificação de alguém como branco, já que, em nosso país, a classificação racial se dá principalmente com base na aparência física das pessoas (NOGUEIRA, 2007 [1954]).

Porém, se considerado que a percepção de alguém como branco encerra sentidos que vão além da mera descrição dos dados supostamente objetivos, como cor da pele ou textura dos cabelos, ensejando diferenças de tratamento e posição social comumente marcadas pelo racismo, é possível entrever que a brancura observada nos corpos se projeta para além deles, ou seja:

\footnotetext{
[...] não há nada espontaneamente visivel na cor da pele, no formato do nariz, na espessura dos lábios ou dos cabelos, ou mais fácil de ser discriminado nesses traços do que em outros, como o tamanho dos pés, a altura, a cor dos olhos ou a largura dos ombros. Tais traços só têm significados no interior de uma ideologia preexistente (para ser preciso: de uma ideologia que cria os fatos, ao relacioná-los uns com os outros), e apenas por causa disso funcionam como critérios e marcas classificatórios (GUIMARÃES, 1997, p. 47).
}

Como salientado, é justamente o conjunto de significados a partir dos quais conceituamos a brancura que interessa a este trabalho. Na sessão que se segue, essa discussão será efetivada a partir da análise de entrevistas semiestruturadas realizadas com dez professores da educação básica, autoclassificados negros e brancos, que rememoraram sua trajetória de vida, com destaque para sua trajetória escolar. 
Nos depoimentos dos professores participantes da pesquisa, a brancura se evidenciou como um valor, um ideal ético, estético, econômico e educacional que pessoas negras e brancas buscariam alcançar ao longo de sua trajetória de vida, fosse simbolicamente, por meio do cultivo de comportamentos atrelados à brancura, fosse corporalmente, por meio da adequação do corpo para corresponder às características que se convencionou relacionar a esta: cabelo liso, nariz fino, pele clara (fala de Carolina'1).

Essas associações positivas entre brancura e valores davam sustentação à ideia de que ser branco era um privilégio que assegurava maior aceitação social ou vantagem, descritas em passagens como a abaixo destacada que se referem à tentativa, por parte do entrevistado, de conceituar o que significava ser "um negro de alma branca":

Negro de alma branca, isso é o seguinte, se a pessoa - o que eu entendia na época,né? - se a pessoa era trabalhadora, era boazinha, era legal, honesta, tudo, então ela tem todas as características de um branco, só que ela é negra[...] "Aqueles negros são negros de alma branca". Então, quer dizer que eles tinham todas as características, todos os adjetivos, todas as qualidades do branco. (Samuel, branco)

No excerto anterior estão descritas todas as qualidades do branco, segundo concepção partilhada pelos familiares do entrevistado e que foram alvos de críticas por parte do docente. Vê-se que ao branco foram associados valores positivos como trabalho, bondade, honestidade, a princípio negados a pessoas negras que puderam cultivá-los em situações particulares.

O deslocamento da brancura e dos valores a ela associados para caracterizar pessoas negras sugere a "realidade autônoma" (COSTA, 1990, p. 4) dos significados de ser branco. No exemplo anterior, ainda que pessoas negras apresentassem as mesmas características e comportamentos associados à brancura, esses significados se mantiveram inalterados. Daí que para explicar a existência de negros trabalhadores e honestos, cujo corpo não coincidia com as construções raciais que pesavam sobre ele, fosse necessário considerálos simbolicamente brancos, pois seus comportamentos seriam exclusivos desse grupo racial.

As explicações do comportamento de pessoas e grupos baseadas em dicotomias raciais perpassaram boa parte das entrevistas. Nesses trechos a

De modo a preservar o anonimato dos participantes todos os nomes são fictícios. 
brancura configurou-se como sinônimo de características que os entrevistados não necessariamente reivindicaram para si, nem utilizaram para se referir a suas próprias experiências, mas que pareceram se relacionar a um "branco genérico": positivamente retratado e, muitas vezes, descrito de maneira distante. Além de bondoso, trabalhador e honesto, esse branco genérico seria também belo, já que os docentes foram unânimes ao mencionar a existência de um padrão de beleza que valoriza a brancura, principalmente em se tratando de mulheres:

\section{[...] a mulher negra, acho que ela leva muita desvantagem perante a mulher branca} em todas as oportunidades. Basta você ver o referencial de beleza na nossa sociedade.

(Samuel, branco)

E boa aparência não é você ter o cabelo arrumado, você ter uma roupinha legal. Não é isso. A boa aparência é você ser branco. (Carolina, negra)

Para mulher branca é mais fácil. Eu sempre achei mais fácil ser mulher branca. Porque eu falo: a mídia, a vida, o padrão europeu já a coloca como modelo, já a coloca como a bonita, e se ela ainda cai pro lado do ser loira acabou, ela já está aprovada de imediato. (Sandra, negra)

A correlação entre brancura e boa aparência citada por Carolina foi amplamente discutida pelos entrevistados nas reflexões sobre as oportunidades de trabalho diferenciadas de acordo com a pertença racial. A exigência de boa aparência, principalmente no caso das mulheres, foi avaliada como aspecto vantajoso para as mulheres brancas na escolha de candidatas a emprego, fato já investigado em pesquisas acadêmicas e considerado na elaboração de lei específica que coíbe a utilização do termo "boa aparência” em anúncios de emprego (DAMASCENO, 2000).

A menção de Sandra a um tipo específico de brancura - a loira - revela que quanto mais próxima a mulher estiver do referencial europeu, mais facilitada seria a inserção social e sua aprovação imediata, ao contrário de mulheres negras que ocupariam uma posição de desvantagem perante a mulher branca.

Indagado a respeito dos contextos de emergência de tal associação, Samuel atribuiu à colonização europeia a construção e imposição de um referencial de beleza que teria permanecido inalterado desde então. A manutenção desses modelos de estética branca foi atribuída pelos docentes à mídia e aos próprios brancos que, como beneficiários do padrão de beleza, o teriam incorporado sem grandes questionamentos: 
O modelo de beleza é branco. Abre uma revista e é só isso. Diversidade não está na revista, na TV. (Márcio, branco)

Eu acho que o branco... Ele, ele tem uma ideia de naturalização da cor muito forte, a... É natural pra eles que o branco, eu acho né, que ele ache que o branco é mais bonito, que o branco seja mais inteligente, acho que pra eles é natural. (Roberto, negro)

No trecho do depoimento de Roberto não apenas encontra-se ratificada a associação entre brancura e beleza, como se verifica outra associação: brancura como indicativa de inteligência. Na avaliação do docente, tais associações seriam naturais para pessoas que se percebem brancas devido a um processo de naturalização da cor. Nesse sentido, a percepção da cor indicaria comportamentos e habilidades dos indivíduos que portam no corpo a brancura, sendo estas tomadas como naturais e não como fruto de construção sociohistórica, o que indica a relação entre o que estamos chamando significados de ser branco e a aparência dos sujeitos. Dito de outro modo: as dimensões corporal e simbólica não podem ser pensadas separadamente, elas funcionam como um sistema de retroalimentação no qual a percepção das características físicas permite inferir comportamentos e valores.

Laura, contradizendo em parte as conclusões de Roberto, argumentou que significados de ser branco seriam construídos e incorporados à experiência branca, não apenas de maneira irrefletida. Para a entrevistada, pessoas brancas teriam elaborado e cultivado deliberadamente os significados positivos atribuídos à sua raça em defesa de seus interesses. Ao responder à pergunta "o que significa ser branco?" ela destacou:

Então, o que hoje é ser branco? É um emprego ser seu, é a sociedade, o respeito, você não tem que ficar sendo o melhor, não, o básico já está bom. E é muito ruim, essa sensação ainda é muito ruim, por mais que você esteja conversando, que você esteja ali, mas é muito ruim, não é uma sensação boa. E saber que as coisas não se constroem a partir disso, não deveria. Ou que muita coisa exatamente não é verdadeira, não é na sua essência exatamente por conta disso, porque os valores estão nesse tipo de coisa. E as pessoas introjetaram esses valores, todo mundo, por questão até de comodidade, de fortalecimento do clã, então introjetaram. " $E$ isso mesmo e acabou”. Então... Mesmo... Desde os revolucionários, os intelectuais, eu acho um absurdo isso vir a partir deles, alguns camuflados, outros descaradamente. E aí a gente está na mão de quem? (Laura, negra)

No trecho acima se destacam diferentes dimensões dos significados de ser branco: sua funcionalidade - os ganhos sociais e psicológicos para aqueles que os mantiveram e elaboraram; os motivos que levaram a sua elaboração - "fortalecimento do clã"; um grupo que teria introjetado tais significados composto por revolucionários e intelectuais; o olhar e avaliação de um “outro" racial sobre esses significados, neste caso, uma mulher negra. Para 
Laura, brancos formariam um clã com privilégios como o acesso facilitado ao emprego e ao respeito. Sua pertença racial asseguraria às pessoas brancas facilidade para se destacarem socialmente - você não tem que ser o melhor, o básico já está bom. Uma vez introjetados os valores associados à brancura, haveria pouco ou nenhum empenho para questioná-los, implicando o processo de naturalização descrito por Roberto.

A escolha da palavra clã para se referir aos brancos no coletivo é bastante curiosa, já que um clã se define como um conjunto de pessoas unidas por parentesco (não necessariamente biológico) e linhagem, possuindo um ancestral comum que pode ser apenas imaginado (FERREIRA, 1993). A ideia de clã evidencia a percepção dos brancos como integrantes de um coletivo cujas ações ou omissões seriam compreendidas em função de sua lealdade a esse grupo, contrariando a crença de que ser branco é se encarar e ser encarado como indivíduo comprometido apenas com seus interesses pessoais (PIZA, 2002).

Contestando a avaliação de Laura, Vitória sugeriu que uma das vantagens de ser branca se relacionaria à possibilidade de ser tratada com individualidade: Sabe, ninguém nunca me chamou de branquela. Eu tenho nome, eu tenho identidade (Vitória, branca). No contexto do depoimento de Vitória ter nome e identidade significou não ser referida como membro de um grupo racial, ao contrário de pessoas negras com as quais a entrevistada convivia, especialmente seus alunos, denominados racialmente de maneira mais frequente - aquele negrinho -, conclusão que se coaduna à formulada por Piza de que o "lugar do negro é o seu grupo como um todo e do branco é o de sua individualidade. Um negro representa todos os negros. Um branco é uma unidade representativa apenas de si mesmo" (PIZA, 2002, p. 72).

Nesse mesmo sentido, Roberto, ao avaliar as diferenças de tratamento dispensado a mulheres negras e brancas destacou:

Tinham algumas pessoas que eram negras e a gente chamava "negra fulana", "negra Dora", por exemplo, que era prostituta. Se a prostituta era branca não tinha o adjetivo na frente, era sempre só o nome, mas se era negra, aí tinha aquele adjetivo "nega fulana". (Roberto, negro).

No caso acima o adjetivo que denotava a pertença racial foi utilizado para marcar mulheres cuja conduta sexual era condenada na cidade em que Roberto crescera e reforçava estereótipos que associavam a negritude a tais condutas. Já mulheres brancas que se comportavam de maneira semelhante não representavam seu grupo racial, eram referidas pelo nome. 
Vê-se que, em se tratando de brancos, a tensão entre indivíduo e grupo nem sempre gerou contradições, já que os autodeclarados brancos, Vitória e Samuel, identificaram momentos em que foram privilegiados por sua pertença racial - beneficiados como integrantes do grupo branco - ao mesmo tempo em que a docente avaliou ter sido tratada com individualidade.

As diferentes avaliações expressas nas falas de Vitória e Laura podem decorrer da pertença racial de ambas. Vitória, sendo branca, pôde usufruir os benefícios de tal classificação, dentre eles o tratamento individualizado. Já Laura, pertencente ao grupo racial negro e frequentemente referida nesses termos, encarou a si mesma como integrante de um grupo, identificando brancos da mesma maneira.

O apelo à individualidade de brancos - nunca me chamaram de branquela (Vitória), me considero uma pessoa (André) - foi mais visível nas descrições que não envolveram a ideia de privilégio racial, aqui entendido em bases institucionais e/ou estruturais, ou seja, que constroem lugares sociais desiguais para brancos e negros, com vantagem para os primeiros. A ideia de que brancos compunham um grupo racial tornou-se explícita quando entraram em jogo as declarações acerca do privilégio de ser branco, expresso na conclusão de que ser considerado bonito, inteligente, trabalhador, bondoso $e$ honesto em função da brancura resultou em uma maior possibilidade de inserção social. A metáfora da sociedade como espaço de portas abertas para a recepção de pessoas brancas sintetiza essa percepção:

Nesses excertos as portas da pesquisa acadêmica, do mercado de trabalho e da sociedade em geral estiveram abertas para brancos. Apenas Sandra frisou uma segunda exigência: no caso de mulheres brancas, para que as coisas fluíssem ainda melhor, seria necessário ser bonita. O que demonstra que, na opinião da entrevistada, a correlação entre brancura e beleza nem sempre está disponível ou é uma condição real para mulheres brancas.

[...] lógico, como branca, eu tive todas as portas abertas, mesmo que fosse uma portinhola que eu tivesse que ficar de quatro, mas a porta estava aberta para mim (Vitória, branca).

Ela [uma pesquisadora] se especializou em História da África, ela é branca e todas as portas ela falou que se abriram pra ela, porque um branco quando vai pesquisar alguma coisa de negro é tudo muito mais fácil (Carolina, negra).

[...] o branco tem as portas, todas as portas estão abertas pra ele, para o branco (Samuel, branco).

[...] para as mulheres brancas a coisa flui um pouquinho melhor, você pode não ser tão intelectualizada, mas se você é bonita as portas se abrem (Sandra, negra). 
Para os entrevistados, a materialização dos sentidos de ser branco naqueles assim classificados funcionaria como chave que abre as portas da sociedade, ilustrando a correlação e retroalimentação entre privilégios simbólicos e estruturais em se tratando da raça branca, e indicando que, para aqueles reconhecidos socialmente como brancos, sua pertença racial e os significados construídos em torno dela não são vividos separadamente.

Além de dimensões não materiais, representadas pela positividade atrelada à brancura, e do privilégio na assunção de postos de trabalho, os docentes mencionaram que ser branco correspondia a ser proprietário e ter renda melhor se comparada a vizinhos, mesmo em contextos que eles classificavam como pobres:

Depois eu fui perceber que meus amigos mais pobres eram os meus amigos pretos e que eu morava numa casa e os proprietários eram meus amigos brancos (Sara, ambígua).

A Bahia tem uns apartheids, tem uns bairros mais ricos, são os bairros de gente da cor da pele branca, ai aqueles bairros cada vez mais pobres são mais negros, tem uns apartheids assim que são evidentes (Roberto, negro).

Eu achava que as famílias... Hoje eu penso assim, na época eu não sacava isso, mas as famílias brancas talvez tivessem mais estrutura financeira do que as famílias negras (Samuel, branco).

Assim, sujeitos brancos, individualizados e supostamente sem raça, destacaram a existência de uma estrutura que os beneficiaria, paradoxalmente, em virtude de sua identificação como membros de um grupo socialmente valorizado. Foi na assunção dos privilégios que a brancura deixou de ser apenas um conjunto de significados simbólicos para configurar-se como condição social favorável para os autoclassificados brancos:

Pesquisadora: O que significava para você ser branco no contexto da infância?

Samuel (branco): A idealização já era branca, e como uma criança eu via uma questão de aceitação, de poder transitar por qualquer lugar, de poder chegar, de poder assim como se diz, enfim, ser aceito pela sociedade, era uma questão de aceitação, eu via isso aí.

Sobressai do excerto a palavra aceitação, tantas vezes reiterada e que não se limita à autopercepção como branco, mas ao efeito dessa percepção na relação com os outros. A palavra aceitação carrega em si sentidos de aprovação, acolhimento e crédito, resumidos no efeito de poder transitar em qualquer lugar. Efeito que se concretiza a partir de uma estrutura que o antecede e que foi nomeada pelo entrevistado como uma idealização branca. 
Em decorrência da idealização branca e da aceitação incondicional, o branco figurou nos depoimentos como modelo de sucesso (fala de Márcio), em diferentes âmbitos: na vizinhança, no ambiente de trabalho e na escola. Esse modelo foi problematizado em críticas a episódio sem que os sujeitos mobilizaram a ideia de raça em favor dos brancos de maneira mais explícita, especialmente por meio da discriminação racial. Se ser branco significou ser bom e legal, como anteriormente destacado, essas caracterizações positivas contradisseram, ao menos em parte, algumas imagens elaboradas a respeito dos brancos como discriminadores.

Desse modo, para esses docentes, a única associação negativa agregada à brancura foi a opressão. Fosse para incluírem a si mesmos como opressores, fosse para se distanciarem desse grupo, os entrevistados indicaram que a maioria das situações de preconceito e discriminação racial que haviam presenciado foi efetivada por pessoas brancas que conheciam, quando não por eles mesmos. Porém, entre os autoclassificados brancos, essa associação - brancura como sinônimo de opressão - foi diretamente explicitada apenas por Márcio:

O homem branco tem a carga de ter sido opressor. Mesmo que você não queira, vem essa imagem. Foi o grande opressor, em termos de racismo, de sexismo. Não é uma imagem muito positiva, não dá muito orgulho. [...] Na verdade, nunca tive muita identidade com isso, minha família foi muito privilegiada, me possibilitou pensar diferente (Márcio, branco).

A família mestiça foi lembrada como suporte para pensar diferente a condição de ser branco. Na concepção do entrevistado, essa condição não era uma imagem positiva, já que a brancura estava associada à elaboração do racismo e do sexismo; assim, sua materialidade em seu corpo não the era motivo de orgulho.

Note-se que o adjetivo branco foi utilizado para qualificar a palavra homem, sugerindo que, na elaboração de sua reflexão, Márcio não se referia aos brancos como um grupo homogêneo, mas dividido em função do sexo. As ações desse grupo específico não teriam apenas culminado no racismo, mas também seriam responsáveis pela construção do sexismo, indicando uma primeira hierarquia entre brancos baseada no sexo, além de uma origem comum para diferentes opressões, neste caso, opressões de gênero e raça.

Outros docentes autoclassificados brancos se referiram à opressão, porém de maneira indireta, por meio das diversas críticas feitas à ideologia racista ou às condutas discriminatórias, mostrando a dificuldade que tinham em identificar-se como parte do grupo opressor, como mencionado por Márcio. 
Fato significativo, já que mesmo tendo participado de curso que abordava a desigualdade racial e entrevista em que algumas questões giravam em torno da referida temática, esses professores encararam a si mesmos como indivíduos não necessariamente comprometidos com uma estrutura excludente.

Já para os entrevistados negros, a brancura e a opressão foram correlacionadas de maneira explícita. Houve caracterização recorrente a respeito do poder do olhar do branco nos depoimentos coletados junto aos negros. Todos se referiram ao olhar de pessoas brancas com as quais tiveram contato, especialmente aquelas desconhecidas, como um olhar que ameaçava e constrangia em diferentes situações:

Quando eu vejo pessoas brancas me olhando [...] fico naquela coisa "Será que vão me maltratar? Será que vão me discriminar?" Mas, difícil acontecer isso, mas, assim, sempre tem alguma coisa, ele sempre vai falar alguma coisa, que vai deixar bem claro, demarcado, que ele é branco e que eu sou negra (Carolina, negra).

Eu acho que o branco não tem ideia do que sejam os olhares. Eu acho que o olhar é uma coisa... Acho que o branco não tem ideia do que seja o poder do olhar, um olhar que te fere, um olhar de desconfiança por você ser negro, ele não tem ideia... (Roberto, negro).

Sinto essa violência, até mesmo na questão do olhar (Laura, negra).

Eu me senti, digamos, em alguns momentos, incomodada. Pensando "que lugar é esse?", mas em momento algum houve destrato, mas houve olhares (Sandra, negra).

Nesses excertos, a brancura foi relacionada não apenas à opressão, mas foi tomada como ameaçadora. O medo do outro - branco - foi sintetizado pelo poder de seu olhar. Um olhar nem sempre indicativo de preconceito, mas que, a partir de vivências anteriores de opressão racial, os docentes aprenderam a interpretar como uma discriminação em potencial, que pôde ou não se concretizar, mas cuja percepção foi fonte de angústia e desconfiança, chegando a ferir sua subjetividade: um olhar que te fere.

Carolina também destacou o esforço de brancos por manter as fronteiras raciais demarcadas por meio de falas ou ações. Mesmo que tal demarcação não necessariamente chegasse a se transformar em discriminação, ela pareceu funcionar como uma lembrança das hierarquias raciais que se fazem presentes no momento da classificação racial dos sujeitos.

Esse medo do que o branco possa fazer ou pensar faz supor que a brancura como bondade não foi sempre uma associação possível para todas as pessoas. Pelo contrário, no caso dos depoimentos acima, a brancura pode ser percebida como algo a ser temido, dimensão para a qual pessoas brancas dificilmente estão 
atentas, pois, como salientado por hooks² (1999, p. 169, tradução minha):

Socializadas para acreditar na fantasia de que a branquitude representa bondade, e tudo o que é benigno e não ameaçador, muitas pessoas brancas assumem ser essa a concepção de branquitude adotada também pelos negros. Elas não se dão conta de que a maneira como a branquitude se impõe à vida negra - frequentemente, de forma aterrorizante de um poder que fere, machuca e tortura - é o que, em realidade, rompe a fantasia da branquitude como representativa da bondade.

Essas associações negativas entre brancura e valores estão estritamente relacionadas àquelas avaliadas como positivas, já que a positividade de ser branco foi quase sempre referida nos depoimentos em contraposição à negatividade de ser negro, de onde surge a concepção de brancura como opressão. Desse modo, negritude e brancura são construções que, embora opostas, se reforçam mutuamente (DÁVILA, 2006, p. 27). Sustenta esta relação um significado primeiro, aparentemente óbvio, mas cuja construção implica complexas hierarquizações de raça: ser branco é não ser negro. Isso não significa, contudo, que a condição de branco ou as conceituações a respeito da brancura não apresentem um núcleo próprio, mas sim que esse núcleo é basicamente excludente e depende com intensidade das construções que faz a respeito daqueles que não o habitam. Essa exclusão primeira sugere que ser negro é ter acesso impedido aos significados de ser branco, exceto quando negros tornamse simbolicamente brancos, reforçando a ordem hierárquica dos significados de ser branco e evidenciando a ideologia racial que dá base a eles.

A característica generalizada da brancura assumida por boa parte das construções que opõem negro versus branco sugere que mesmo que parte das associações positivas entre brancura e valores não estejam seguidas de exemplos concretos oriundos de experiências vividas pelos sujeitos da pesquisa, e que brancos não efetivem a discriminação racial, apesar de terem seu olhar associado a tal possibilidade, tais características foram atribuídas aos brancos como grupo. Essas associações generalizadas podem ser compreendidas a partir da proposição de Costa (1990, p. 4) de que

Para o sujeito negro oprimido, os indivíduos brancos, diversos, em suas efetivas realidades psíquicas, econômicas, sociais e culturais, ganham uma feição ímpar, uniforme e universal: a brancura. A brancura detém o olhar do negro antes que ele penetre a falha do branco. $A$ brancura é abstraída, reificada, alçada à condição de realidade autônoma, independente de quem a porta enquanto atributo étnico ou, mais precisamente, racial. A brancura [...] funciona como um pré-dado, como uma essência que antecede a existência e manifestações históricas dos indivíduos reais, que são apenas seus arautos e atualizadores. O fetichismo em que se assenta a ideologia racial faz do predicado branco, da brancura, o "sujeito universal e essencial" e do sujeito branco um "predicado contingente e particular".

2 Por questões ideológicas, a autora bell hooks grafa seu nome e sobrenome em letras minúsculas e assim prefere ser referenciada em trabalhos acadêmicos. 
Neste trabalho, não apenas sujeitos negros idealizaram a brancura, abstraindo condições de vida concreta de brancos, como os próprios brancos falaram a respeito de características que não são generalizáveis a todos os membros de seu grupo racial. No texto de Costa, assim como nesta reflexão, a brancura é entendida para além das dimensões do corpo, e a pele branca funciona como "predicado contingente e particular" que, entre outros aspectos, permite que se pressuponham habilidades e condutas de pessoas que portam no corpo esse predicado. É ao conjunto de características que compõe essa pressuposição que vimos denominando significados raciais.

Assim, as experiências dos sujeitos podem remeter aos significados de ser branco ora mencionados, mas nem sempre estão em consonância com tais construções. Por outro lado, a existência de uma idealização branca, ou de um branco genérico, possibilita uma identificação positiva para pessoas que se reconhecem e são reconhecidas como brancas, tal como indica o efeito de aceitação em virtude da pertença racial branca, mencionado por Samuel.

A aceitação e a vantagem foram os únicos significados presentes nos depoimentos de sujeitos brancos que remeteram às suas experiências de vida. Já para docentes negros, o contato com pessoas brancas em suas trajetórias também possibilitou que o branco genérico, positivamente retratado e potencialmente opressor, fosse contrastado a pessoas brancas reais. Nesse sentido, Sara destacou que a convivência com uma de suas irmãs que ela classificou como branca ensejou associações negativas com a brancura:

Eu lembro que era eu que xingava a minha irmã de branquela azeda, de branca podre, eu xingava a minha irmã dessas coisas. Eu achava que minha irmã fazia o cocô mais fedido do que todo o mundo. A minha irmã era muito peidorrenta. A minha irmã é muito branca, muito branquinha e ela era muito cagona de pequena, peidava, então eu cresci associando a branquitude a isso. (Sara, ambígua)

Para além do possível ciúme entre irmãs, em especial pelo fato de uma ser percebida como branca e a outra não, a fala de Sara revela também efeitos da convivência cotidiana na conformação de significados não idealizados de brancura. 
Mas não apenas associações negativas como essa foram rememoradas da convivência mais próxima com pessoas brancas. Carolina ao se lembrar do dia mais feliz de sua vida, quando concluiu seus estudos em nível superior, destacou a participação de pessoas brancas, anjos da guarda, que a teriam motivado a superar as barreiras interpostas à sua escolarização:

Tive a força de resistir pela minha profissão porque não queriam que eu estudasse, sempre vêm com aquelas barreiras. Mas sempre você encontra também anjos da guarda que te ajudam e falam: "Não, vai estudar, depois a gente se entende e tal." Eu tive um capitão ${ }^{1} q u$ ele falava: "Não, você não tem que ir pra faculdade? Vai pra faculdade, deixa esse serviço aqui que depois você me paga com outro dia de sua folga, a gente faz um bem bolado, mas vai pra faculdade". Então eu tive essas pessoas que, graças a Deus, me ajudaram a estudar, a vencer. Tive pessoas brancas que me viram chorando, cansada, ali arrasada por um problema que passei, estar cansada e falar "Vou desistir disso tudo, voltar pra minha terra na beira do meu mar, tomar água de coco, deixar tudo isso." e a pessoa falar "Não, fica aqui, você já lutou tanto, não desista, vá dormir, vá relaxar." e te dar um copo de água e falar assim: "Descansa, relaxa, amanhã é outro dia, você é uma guerreira.", então tem muito isso (Carolina, negra).

1 Carolina havia trabalhado como policial militar antes de exercer a docência.

Essas pessoas brancas mencionadas por Carolina não correspondem à imagem ameaçadora presente nos excertos a respeito do olhar do branco. As caracterizações desse olhar pareceram se referir a brancos desconhecidos, reforçand o a generalidade de tal caracterização e sugerind o que os significados de ser branco apresentam dois patamares: um já citado, correspondente a construções generalizadas, e outro construído na interação e convivência que problematiza ou reforça o anterior.

CONSIDERAÇÕES FINAIS E IMPLICAÇÕES PARA O DEBATE EDUCACIONAL

As significações positivas atreladas à brancura não parecem, a princípio, sinalizar um problema para a construção de uma sociedade menos desigual. No entanto, como visto, tais ideias não aparecem isoladas daquelas relativas aos demais grupos raciais.

Embora a existência de uma estrutura que privilegia sujeitos brancos anteceda suas realizações concretas e favoreça aqueles socialmente reconhecidos como tal, muitos dos docentes entrevistados reconheciam pessoas brancas que não viveram os privilégios que narraram, ou seja, que não tiveram a possibilidade de encarar a própria brancura como vantagem, mas que nem por isso deixaram de construir essa idealização. Assim, problematizar os significados de ser branco não significa expor o preconceito individual dos 
sujeitos ou necessariamente falar a respeito de identidades raciais que favoreçam a prevalência do racismo. Significa prioritariamente questionar a “idealização branca” (fala de Samuel).

Essa idealização é construída em diferentes espaços sociais, dentre os quais figura a escola, instituição que tem sido encarada como produtora e reprodutora de desigualdades raciais e, ao mesmo tempo, se configura como uma aposta de diferentes atores sociais para o combate a elas (GOMES, 2007, 2008).

Todavia, no principal documento que estabelece as diretrizes para a educação das relações étnico-raciais (BRASIL, 2004) esse aspecto é tratado secundariamente em relação à necessidade de ressignificar a negritude. 0 documento salienta a necessidade de "reconhecimento e valorização da identidade, da cultura e da história dos negros brasileiros" como fator fundamental para que todos os alunos sintam-se apoiados e valorizados (idem, p. 5).

Para além dessa proposta, que reflete uma conquista importante no debate educacional voltado para o tratamento adequado da diversidade, as análises ora realizadas sugerem que educar para o combate às desigualdades raciais é também educar para que a idealização branca deixe de ser objeto de desejo para negros e brancos, em outros termos, almejar que a adesão à ideia de supremacia branca que os significados analisados pressupõem seja cada vez menos viável e desejável. 


\title{
The value of whiteness: considerations on a little- explored debate in Brazil
}

\begin{abstract}
This paper lies in the field of debates regarding racial inequalities and is aimed at assessing an aspect dealt with rarely in Brazilian studies: conceptions built in relation to whiteness. To fulfill this aim, semi-structured interviews were done with ten primary school teachers who self-identified as black or white. These interviews sought to understand what "being white" meant to their life histories. Analyses showed that whiteness is seen as an ethical, educational, aesthetic and economic ideal to be achieved by the subjects; it is an idealization built based on depreciation of other racial groups, especially blacks. The conclusion was reached that current discussions on anti-racist education may contribute to deconstructing this idealization.
\end{abstract}

Keywords: Racial Relations. Whiteness. Blackness. Diversity. Education. 


\section{REFERÊNCIAS}

BENTO, M. S. Branquitude: o lado oculto do discurso sobre o negro. In: BENTO, M.A.S.; CARONE, I. (Org.). Psicologia Social do Racismo. Rio de Janeiro: Vozes, 2002. p. 147-162.

BRASIL. Ministério da Educação. Resolução $n \times 0$ 1, Conselho Nacional de Educação, de junho de 2004. Institui as Diretrizes Curriculares Nacionais para a Educação das Relações Etnico-raciais e para o Ensino de História e Cultura Afro-Brasileira e Africana. Diário Oficial da União. Brasília, 2004.

COSTA, J. F. Da cor ao corpo:a violência do racismo. In:SOUZA. N.S. Tornar-se negro: ou as vicissitudes do negro brasileiro em ascensão social. 2a edição. Rio de Janeiro: Edições Graal, 1990.

DÁVILA, J. Diploma de brancura: política social e racial no Brasil 1917-1945. São Paulo: Editora da UNESP, 2006.

DAMASCENO, C. "Em casa de enforcado não se fala em corda": notas sobre a construção social da "boa" aparência no Brasil. In: GUIMARÃES, A.S.A; HUNTLEY, L. (Org.).Tirando a Máscara: ensaios sobre o racismo no Brasil. São Paulo: Paz e Terra, 2000.

FERREIRA, A.B.H. Novo dicionário da Língua Portuguesa. Rio de Janeiro: Nova Fronteira, 2a edição, 1993.

FRANKENBERG, R. White women, race matters: the social construction of whiteness. Mineapolis: University of Minnesota Press, 1993.

GOMES, N. L. Diversidade étnico-racial em educação no contexto brasileiro: algumas reflexões. In: GOMES, L.N.G. (Org.). Um olhar além das fronteiras: educação e relações raciais. Belo Horizonte: Autêntica, 2007.

A questão racial na escola: desafios colocados pela implementação da Lei 10639/2003.In:CANDAU, V.M.F.; MOREIRA, A.F.B.(Org.). Multiculturalismo: diferenças culturais e práticas pedagógicas. Petrópolis: Vozes, 2008.

GUIMARÃES, A.S.A. Racismo e Anti-racismo no Brasil. São Paulo: Editora 34, 1997.

HARRIS, C. Whiteness as a Property. Harvard Law review. n. 106, june, 1993. 
HOOKS, B. Intelectuais Negras. Representing Whiteness in the Black Imagination. In: FRANKENBERG, R. Displacing whiteness. Durham: Duke University Press, 1999.

NOGUEIRA, O. Preconceito racial de marca e preconceito racial de origem: sugestão de um quadro de referência para a interpretação do modelo de relações raciais no Brasil. Tempo Social, revista de sociologia da USP, v.19, n.1., 2007 [1954].

PIZA, E. Porta de Vidro: entrada para a branquitude. In: BENTO, M.A.S.; CARONE, I. (Org.). Psicologia Social do Racismo: estudos sobre branquitude e branqueamento no Brasil. Rio de Janeiro: Vozes, 2002.

SCHWARCZ, L. M. 0 espetáculo das raças: cientistas, instituições e questão racial no Brasil 1870 - 1930. São Paulo: Companhia da Letras, 1993.

STEYN, M. Novos matizes da "branquidade": a identidade branca numa África do Sul multicultural e democrática. In: WARE, V. (Org.). Branquidade, identidade branca e multiculturalismo. Tradução: Vera Ribeiro. Rio de Janeiro: Garamond, 2004.

RECEBIDO: Dezembro de 2012.

APROVADO: Abril de 2013. 